\title{
Ensaio para uma Teoria da Crença segundo a Concepção Tripartite do Tempo
}

[Essay for a Belief Theory according to the Tripartite Conception of Time]

João Renato Amorim Feitosa®

Resumo: O presente artigo tem como principal objetivo a tentativa de pensar a possibilidade de uma teoria da crença entendida como dividida em diferentes modalidades temporais: presente, passado e futuro. Tendo em vista os trabalhos desenvolvidos por Tarski e Popper acerca do problema da verdade e teorias pragmáticas da linguagem como a de Habermas e Austin, gostaríamos de testar os limites da concepção de verdade enquanto correspondência em relação a uma concepção tripartite do tempo, ou seja, nos perguntamos acerca da validade daquela concepção de acordo com a diferente modalidade temporal dos enunciados. Em um primeiro momento, analisamos os fatores para que um enunciado se torne objetivo, isto é, válido para além do âmbito subjetivo, de acordo com a concepção usual de tempo, para em seguida apresentar alguns exemplos de uso prático das modalidades temporais dos enunciados na fala cotidiana, e em algumas instituições públicas regidas por regras aceitas coletivamente. Por fim, nos perguntamos se as mudanças de paradigma em relação à nossa concepção de tempo seriam fatores chave no que diz respeito à determinação das regras de validação dos enunciados que o têm como referência, e as consequências práticas desse tipo de enunciado.

Palavras-chave: Verificação. Justificação. Tempo. Convenção.

\begin{abstract}
This article has as main objective the attempt to think the possibility of a belief theory understood as divided in different temporal modalities: present, past and future. In view of the work developed by Tarski and Popper on the problem of truth, and pragmatic theories of language such as of Habermas and Austin, we would like to test the limits of the conception of truth as correspondence in relation to a tripartite conception of time, that is, we ask ourselves about the validation of the choice according to the different temporal modality of the statements. At first, we analyze the factors so that a statement becomes objective, that is, valid beyond the subjective scope, according to the usual conception of time, and then to present some examples of practical use of the temporal modalities of the statements in the speaks every day, and in some public institutions governed by collectively accepted rules. Finally, we ask ourselves if the paradigm changes in relation to our conception of time are possible key factors with regard to the determination of the validation rules of the statements that have them as a reference, and the practical consequences of this type of statement.
\end{abstract}

Keywords: Verification. Justification. Time. Convention.

\footnotetext{
${ }^{*}$ Mestre em Filosofia pela Universidade de Brasília (UnB). Atualmente realiza doutorado em filosofia e graduação em química pela mesma instituição. E-mail: joaofeitosafil@gmail.com. ORCID: https://orcid.org/0000-0002-8784-7233.
} 


\section{O problema acerca do conheci- mento objetivo}

Um dos problemas clássicos da filosofia consiste na seguinte questão: "o que diferencia um saber de uma opinião?". Já não seria a 'opinião' um tipo de 'saber'? Quais são os critérios que me asseguram que aquilo que afirmo consiste num conhecimento 'verdadeiro' ou até mesmo 'seguro'? A essas questões poderíamos acrescentar uma outra, qual seja, qual o fundamento da concordância entre dois indivíduos acerca da validade de um juízo ou proposição? Na história da filosofia encontramos uma larga tradição de pensamento orientada a esse tipo de discussão. Pelo menos desde os filósofos gregos, a busca pelas condições para um "conhecimento verdadeiro" que separasse opinião de saber se fez presente nas obras dos principais filósofos do ocidente. Essa é uma característica dominante nas obras de Platão (p. ex. República [478b], Teeteto [145e /188a], Eutidemo [277b]) e Aristóteles (p. ex. Metafísica [982b/ 1004b]). Sobretudo na modernidade tal recorte temático é fortemente presente em Bacon (p. ex. Instauratio Magna e Os progressos do Conhecimento [282 IV]), Descartes (p. ex. Princípios da Filosofia [parte I $\S$
43], Meditações), Locke (p. ex. Ensaio [int. § 3]), Leibniz (p. ex. Novos Ensaios [Livro IV]), Hume (p.ex. Investigação [Seção IV]) e Kant $t^{1}$ (p. ex. KrV $V^{2}$ [A 770/ B 803]). Não menos importante que o tratamento oferecido pelas epistemologias modernas ao problema do conhecimento é o novo ferramental teórico oferecido pela filosofia da linguagem desenvolvida no século $\mathrm{XX}^{3}$ para avaliar problemas epistemológicos. Gostaríamos de pensar o problema acerca da objetividade dos juízos especificamente em sua relação com o tempo assumindo-o como instância necessária da referenciação das proposições a partir de uma perspectiva pragmática da linguagem, especificamente assumindo a proposição ou juízo como "atos através dos quais um falante gostaria de chegar a um entendimento com outro falante sobre algo no mundo" 4 . A definição clássica de conhecimento como "crença verdadeira justificada" enseja em cada um de seus conceitos um conjunto de problemas tratados pelos diferentes domínios da teoria do conhecimento; portanto, aqui nos preocupamos apenas com o caráter da crença em primeira instância, ainda que avaliemos sua função em relação aos outros dois domínios teóricos que compõem aquela

\footnotetext{
${ }^{1}$ Sobretudo em Kant fica evidenciada a orientação teórica à sistematização de todos os saberes presente na modernidade, como ele mesmo afirmou, "a nossa época é a época da crítica, a qual tudo tem que submeter-se".

${ }^{2}$ Doravante, sigla utilizada para Crítica da Razão Pura.

${ }^{3}$ Habermas (1988, p. 15. § $1^{\circ}$ ) dá uma bela interpretação para o significado da "virada linguística" em relação ao paradigma moderno: "[...] As relações entre linguagem e mundo, entre proposição e estado de coisas, substituem a relação sujeito-objeto. O trabalho de constituição do mundo deixa de ser uma tarefa da subjetividade transcendental para se transformar em estruturas gramaticais."

${ }^{4}$ Ibidem, p. 65. $\S 1^{\circ}$. Habermas chama o que aqui estou tratando como juízos ou proposições de "proferimentos linguísticos".
} 
definição clássica (veja DUTRA, 2001 p. 9)5. Desse modo, entendemos aqui que a crença guardaria uma estreita relação com o caráter de verdade sob o ponto de vista da conferência ou não de objetividade a um juízo por parte de um interlocutor, ou seja, entendemos verdade como validade objetiva e a crença como uma disposição em conferir ou não essa validade a um juízoㅇ. Assumindo esses pressupostos, nós nos perguntamos em seguida como é atribuída validade a um juízo que envolva categorias temporais (ontem, hoje, amanhã) e quais os critérios estabelecidos para a concessão de validade em cada um dos momentos do tempo em sua concepção tripartite ${ }^{7}$.

Imaginemos por um momento uma situação hipotética. Um sujeito diz para seu amigo: 'está chovendo em Brasília'. Os dois se encontravam num local de Brasília onde, naquele instante em que a frase foi dita, atualmente chovia. O outro amigo então confirma 'sim, realmente está chovendo'. Ele poderia também dizer 'choveu em Brasília ontem'. De posse de um jornal que continha a informação de que havia chovido um dia antes em Brasília, o outro amigo confirma 'sim, realmente choveu em Brasília’. Numa outra situação, o pri- meiro amigo, ao avistar um conjunto de nuvens escuras se aproximando do céu de Brasília, diz: 'Logo vai chover em Brasília'. Será que o outro amigo responderia 'sim, realmente, logo vai chover em Brasília', com a mesma 'intensidade' com que concordava com a primeira afirmação? E se a primeira frase fosse 'Deus é o criador dos céus e da terra' ou 'a essência do nada é a sua concomitância com o devir'? A partir desses exemplos, podemos classificar três tipos de crença: 1) em enunciados metafísicos de maneira geral (atemporais); 2) as que dizem respeito a uma situação no tempo presente. 3) as que dizem respeito a uma situação passada. 4) as que dizem respeito a uma situação no futuro. Disso também se segue que para cada tipo de crença citada acima encontraríamos um critério de atribuição de validade diferente: 1) Coerência lógico-gramatical e crença subjetiva; 2) princípio de verdade como correspondência; 3) '1' ou disposição voluntária a crer no juízo emitido; 4) indução. Não queremos com isso dizer que aqui se esgotam todas as possibilidades de modalidades da crença, tampouco dos critérios para a justificação de cada tipo de crença, mas queremos apenas tomar

\footnotetext{
5Isto é, "teorias da crença, teorias da verdade e teorias da justificação".

${ }^{6}$ Isto é, não estamos pensando o caráter lógico-formal das regras de verificação ou do conceito de verdade, mas sim pretendemos pensar a validade como aceitação coletiva de um argumento, proposição ou juízo, portanto, juízo verdadeiro para a presente investigação é aquele no qual se crê coletivamente, mais especificamente estamos pensando em juízos que contêm referência ao tempo.

${ }^{7} \mathrm{Ou}$ seja, diante do que foi dito no rodapé acima, queremos avaliar as condições para que um juízo seja validado, sob aquela perspectiva, quando ele diz respeito a um acontecimento passado, presente ou futuro. É importante ressaltar aqui que estamos pensando o tempo como um elemento essencial da constituição da cognição humana, tal qual Kant o pensou na KrV (p.ex. B 52), tomando os acontecimentos no tempo como referência empírica necessária (a priori) aos objetos (veja B 118). Desse modo, a qualquer enunciado com referência a uma das três partes do tempo recairia uma demanda de validade material.
} 
este fio condutor a fim de testar algumas hipóteses.

\subsection{Enunciados metafísicos e crença subjetiva}

Se alguém me diz 'a origem do universo deriva de uma causa inteligente', eu posso questionar esse sujeito acerca das razões ou motivos pelos quais ele justifica a sua afirmação. Ele poderia responder: 'tudo no universo tem uma causa, e a primeira causa só pode ter surgido de uma vontade, etc'; se nesse momento eu tomasse o princípio de verdade enquanto correspondência como critério para avaliar a justificação desse enunciado, certamente eu diria que ele não diz respeito a nada que possa ser dado em uma experiência; contudo, se eu tomo como critério de justificação a coerência lógica, tudo parece normal nesse enunciado. Isto é, os enunciados metafísicos, como não contam com uma referência na experiência, só podem contar com a coerência lógica do sistema de enunciados, ou seja, as regras sintáticas e semânticas inerentes à linguagem utilizada 8 . Todos os sujeitos que partilham de uma posição metafísica específica acerca de Deus, por exemplo, ao reunirem-se em assembleia, estando de posse de um livro comum, e de um conjunto de enunciados estabelecidos como verdadeiros, estariam de comum acordo com o sujeito que enunciou que 'a origem do universo deriva de uma causa inteligente'. Assim, se o mesmo enunciado fosse proferido em um ambiente no qual vigem diferentes enunciados estabelecidos como verdadeiros, se não fosse tomado como falso, ao menos seria como duvidoso, vazio, ou insuficiente de provas.

Um sujeito pode também crer na existência de entidades metafísicas de modo que, ao tentar expressá-las sob conceitos, só consiga dizer algo como 'só eu posso sentir', 'é algo que diz respeito à interioridade, ao espírito, etc'; Neste ponto, o sujeito pode ao seu bel prazer associar com coerência lógica impecável qualquer argumento que sustente a tese que lhe aprazer acerca de entidades metafísicas. O resultado positivo dessa associação - ou, se quisermos, articulação de enunciados por via de regras lógicas que garantam sua coerência em uma linguagem - isto é, a adequação correta dos enunciados individuais ao conjunto de regras, gera no sujeito que a proferiu a impressão de que sua dedução resultou em uma ampliação de seu conhecimento. Assim, um líder religioso que tenha sua religião baseada em um conjunto de crenças ou preceitos aceitos como ver-

\footnotetext{
${ }^{8}$ Essa limitação quanto ao escopo de validade de enunciados metafísicos é produto direto do criticismo kantiano. Vide: (KrV B 22), (Prol AA 04. 277.) Kant constatou que a metafísica “[...] ocupa-se ainda de conceitos puros da razão que jamais são dados em nenhuma experiência possível, conceitos cuja realidade objetiva (fato de que não são meras fantasias) e asserções cuja verdade ou falsidade não podem ser confirmadas ou descobertas por nenhuma experiência." (Prol AA 04. 327.).
} 
dadeiros, pode tomar qualquer trecho desse conjunto de crenças, e daí deduzir as mais diversas consequências, que na maioria das vezes advém a um resultado prático. A plateia, atenta à fala do líder, profere palavras de ordem a cada vez que aquele, com entonações e modos de fala adequados a cada momento, grita com entusiasmo alguma passagem de seu conjunto de crenças, corroborando assim, para a verdade e a justificação daquilo que foi dito.

É importante perceber que uma crença metafísica não implica necessariamente em uma crença subjetiva. No caso em que se trata de uma reunião de um grupo que aceita um conjunto de crenças, essa crença é coletiva, contudo, não se pode dizer que é objetiva. Objetividade é um critério diferente de aceitação coletiva, apesar desta última contribuir para o cumprimento do primeiro. Desse modo, em um grupo que estabeleça formalmente um conjunto de enunciados aos quais se atribua a crença de verdadeiros, contribui ao mesmo tempo o caráter da crença subjetiva, de modo que a concordância coletiva ocorre simultaneamente a uma crença subjetiva. Esse tipo de crença pode conter predicados temporais ou predicados espaciais, mas nunca fazem referência a algo da experiência, e por isso dissemos que a sua justificação não pode ser tomada por via do princípio de verdade enquanto correspondência, pois desse modo é possivel $l^{9}$ tratar os enunciados metafísicos avaliando-os do ponto de vista de sua coerência interna.

Desse modo é possível dizer 'o mundo tem necessariamente um começo no tempo', ou ainda que 'o espaço no qual o mundo está contido é infinito', mas jamais obter para elas uma comprovação que não dependa de nenhuma inclinação subjetiva à adesão de algum sistema metafísico, ainda que esses problemas também digam respeito à física e a geometria. Podemos deduzir, passo a passo, que o mundo tem de ter tido um começo no tempo, pensando o tempo como uma sucessão infinita de momentos, mas não podemos dar uma experiência que comprove isso, nem para o espaço. Porém, dentro de um conjunto de crenças, tais afirmações podem ser tomadas como verdadeiras.

\footnotetext{
${ }^{9}$ Estamos tomando aqui a concepção de verdade enquanto correspondência no mesmo sentido que Alfred Tarski (1944 p. 342) conferiu a ela: "a verdade de uma sentença consiste em seu acordo com (ou correspondência à) realidade" e desse modo "uma sentença é verdadeira se ela designa um estado de coisas existente", mas em um sentido mais forte, no qual o estado de coisas exigiria a materialidade da designação. Karl Popper (1972, p. 50) afirma que aceita "a teoria do senso comum (defendida e aprimorada por Alfred Tarsky) de que a verdade é a correspondência com os fatos (ou com a realidade)". Como aos juízos metafísicos falta uma experiência (realidade) a qual o juízo se refira, eles não são verificáveis segundo aquela concepção. Note que no presente artigo, a experiência subjetiva da crença é considerada um fato mental, subjetivo, não um fato material, objetivo. Portanto, para se avaliar a validade de um enunciado metafísico do ponto de vista de sua coerência interna, devemos abrir mão da noção de verdade como correspondência. Nossa sugestão é avalia-la de um ponto de vista pragmático e fundamentar a verdade de crenças metafísicas na adesão coletiva dos membros daquela comunidade linguística.
} 


\subsection{Enunciados sobre o tempo pre- sente}

Se há na minha frente, no exato momento em que profiro a frase 'ali está um cachorro', um desses animais, e meu interlocutor também vê o animal, nem mesmo surge o problema da justificação desse enunciado. Aqui, surge a questão epistemológica acerca do compartilhamento das faculdades, pois, caso fossem diferentes, poderia não haver concordância entre os dois falantes acerca do enunciado. A concordância entre os dois falantes, num caso como esses, ocorre simplesmente por adesão coletiva? Ambos compartilham da mesma linguagem, e da mesma língua ${ }^{10}$, mas, poderíamos dizer que aí se trata de uma mera concordância com as regras adotadas pela linguagem, pois um exemplar empírico espaço-temporalmente localizado ali se encontra, e nada falta ao enunciado? Podemos pensar em uma situação hipotética na qual um sujeito tenha a vida toda visto aquilo que comumente se designa pelo nome de 'cabra' como sendo um cachorro; Se eu digo 'ali está um cachorro', apontando para o que comumente chamamos por esse nome, certamente ele diria 'não, isto não é um cachorro'. Mas caso se encontrassem o cão e a cabra distantes num pasto, e o primeiro dissesse 'ali está um cachorro', o segundo poderia muito bem aceitar como justificado o enunciado do primeiro, mesmo tomando outro objeto como referência para o mesmo. Nesse caso, haveria uma correspondência entre o enunciado do primeiro falante com o animal cachorro, e o mesmo enunciado, tomado pelo segundo falante como designando outro animal, isto é, a cabra, só pode ser dito corresponder internamente ao segundo falante, mas jamais ao objeto exterior ali dado, pois nesse caso se trataria de um enunciado sobre o tempo presente justificado por coerência subjetiva. Não podemos dizer que nesse caso os dois falantes concordaram acerca do fato, mas somente acerca do enunciado, pois os dois fatos aos quais esse enunciado se refere são diferentes. Como eles são diferentes, o princípio de verdade como correspondência deve valer de maneira individual, pensado segundo a perspectiva de cada falante, e não de uma maneira global, pois nesse caso, esse exemplo contrário parece invalidar o princípio. Do ponto de vista da sensibilidade de cada falante, acredito que mesmo que eles tenham tomado referências diferentes para o mesmo nome, muito provavelmente viram coisas diferentes como referência, isto é, tomando o mesmo sujeito que designava o ani-

\footnotetext{
${ }^{10}$ Segundo FISCHER (2009, p. 12), “Em sua definição mais simples, linguagem significa 'meio de troca de informações'. Essa definição permite que o conceito de linguagem englobe expressões faciais, gestos, posturas, assobios, sinais de mão, escrita, linguagem de programação (ou de computadores), e assim por diante." Tomamos aqui essa definição de 'linguagem', e estamos entendendo 'língua' como as línguas naturais dos diferentes povos (p.ex. Alemão, Inglês).
} 
mal cabra pelo nome 'cachorro', e colocando os dois animais claramente diante dos olhos desse sujeito, ele só designaria um dos dois por esse nome, ficando confuso acerca ou atribuindo outro nome ao outro.

Desse modo, caso o enunciado em questão coincida atualmente e para o mesmo objeto a qual ele se refere, sua justificação está feita. Haveria aí algum elemento de convenção? A descontar o uso da linguagem comum, parecenos que poderia haver alguma concordância entre as faculdades dos sujeitos, ainda que não completamente, mas acerca de alguns requisitos sensíveis mínimos, por exemplo, gozar de uma visão saudável. Porém, ainda que não possa haver elementos de convenção, pode haver afirmações subjetivas em enunciados sobre o tempo presente, tais como 'eu tenho dor', para as quais não pode nem mesmo haver a demanda acerca de sua justificação, pois seu eu digo 'prove que você tem dor', jamais a pessoa poderá me fornecer uma experiência. Assim, pode haver enunciados sobre o tempo presente que podem ser verificados pelo princípio de verdade como correspondência e outros para os quais é sem sentido exigir verificação. Se eu digo 'eu estou na sua frente agora', estando em sua frente, também não há motivos para especular muito acerca da verdade de minha afirmação, a não ser que se trate de uma ilusão perceptual sua.

Nesse ponto, é importante nos aten- tarmos para a questão da ilusão perceptual. O único modo de saber se o que se passa atualmente em sua sensibilidade é ou não uma ilusão perceptual sua é perguntar para outro falante da língua se ele vê o mesmo que você atualmente vê; caso ele concorde acerca do significado dos termos, está tudo bem, ainda que os dois estivessem sobre o efeito de uma ilusão perceptual, isso porque nesse caso mesmo a ilusão perceptual seria para eles objetiva. Assim, um enunciado sobre o tempo presente goza de objetividade segundo o critério de verdade como correspondência, mas no fundo o que está em jogo é a concordância conceitual envolvida na definição dos termos, sendo a correspondência em última instância feita entre o conceito que compõe o enunciado e a forma comum compartilhada da sensibilidade dos falantes.

Podemos pensar que, assim como uma reunião de religiosos, uma reunião de cientistas que estejam tratando de um experimento atualmente presente em um laboratório, exige da parte dos colaboradores individuais que estejam a par de uma linguagem comum e de um conjunto de regras tomadas como verdadeiras. Porém, ao contrário dos enunciados metafísicos, enunciados sobre o tempo presente são convencionalmente aceitos a partir de experimentos que podem ser reproduzidos, e geralmente não são aceitos segundo critérios como autoridade do falante, adesão coletiva por crença subjetiva, etc. 


\subsection{Enunciados sobre o tempo passado}

Se alguém me disser 'ontem eu fui ao cinema', e eu me perguntar pela justificação deste enunciado, jamais poderei saber se a afirmação do interlocutor é verdadeira ou falsa. Nesse caso, ou deverei conferir a ele uma espécie de confiança e acreditar em seu enunciado por mera concessão, caso eu não estivesse naquele momento, ou a justificação do enunciado se dá, caso eu estivesse também naquele momento, pelo critério de verdade como correspondência pensada naquele presente que hoje chamamos de passado. Haveria assim, uma espécie de presente do pretérito no qual aquele princípio pode ser aplicado, de modo que, no momento presente, caso seja enunciado 'ontem eu fui ao cinema', e eu também tiver ido com essa pessoa, a verificação pode se dar por correspondência, caso contrário, ela só pode se dar por concessão. Fatos históricos, notícias, relatos, estórias, nunca são sobre o momento presente. Portanto, nesses casos, se falante e interlocutor não compartilharam da mesma experiência no passado, a verificação dos enunciados só pode se dar pela crença daquele que ouve ou lê acerca da sinceridade daquele que fala. Eu não vivi a Segunda Guerra Mundial, tampouco estava com Neil Armstrong quando este pisou na Lua, portanto as imagens, textos e relatos que me contam sobre esses acontecimentos, rigorosamente falando 11 , não são provas que garantem a verificação desses argumentos segundo o critério de correspondência ${ }^{12}$, Mas isso significa que em qualquer relato sobre o passado é impossível a verificação direta? Quando a nossa mãe nos conta acerca de nosso comportamento quando éramos bebês, podemos verificar este enunciado como alguém que esteve ali presente? Nesse caso, deveríamos acrescentar um fator epistemológico a mais à nossa investigação e dizer que é preciso além de ter vivido o mesmo fato, ter tido consciência dele? Num caso como esses somos obrigados a admitir que também podemos conceder validade aos enunciados de nossas mães acerca de nosso comportamento quando bebês, mesmo não tendo consciência de ter estado lá, por mera concessão. Mas acontece que naquela época, eu não dispunha ainda da mesma linguagem, e consequentemente das regras que sustentam a coerência entre os falantes, tampouco esta-

\footnotetext{
${ }^{11}$ J. Dancy (1990) faz uma distinção entre verificação forte e verificação fraca: "A verificação forte é verificação conclusiva; uma afirmação é conclusivamente verificável se, uma vez que tenhamos a melhor evidência possível para ela, não restar qualquer possibilidade de a afirmação ser falsa." (p. 114). Já uma "afirmação fracamente verificável não é em si fortemente verificável, mas é confirmável ou desconfirmável por recurso a outras afirmações que são conclusivamente verificáveis; isto é, as afirmações fortemente verificáveis podem contar com a evidência a favor ou contra elas" (ibidem). Apresentamos aqui como uma questão se os enunciados sobre o passado seriam, sob esta perspectiva, "fracamente verificáveis", pois sempre são enunciadas no tempo presente, o que inviabilizaria uma "verificação direta" daquele enunciado.

${ }^{12}$ É preciso esclarecer que aqui estamos dando um sentido forte ao critério de correspondência, atribuindo ao presente a única referência empírica capaz de satisfazer as condições (materiais) de validação objetiva daquele enunciado.
} 
vam desenvolvidos plenamente os sentidos, por isso, é como se eu não tivesse vivido o fato, pois faltavam os dois fatores que constituem este último ${ }^{13}$. Assim, um fato passado só é um fato a partir do momento em que eu o presenciei conscientemente, do contrário, ele é a concessão de um enunciado que somente é válido por esse caráter.

É sempre prudente separar o que é fato do que é uma notícia, uma história, um relato, pois estes versam sobre os fatos. Nesses tipos de enunciados, fica bastante evidente uma dependência da confiabilidade do interlocutor para com o falante, de modo que isso se expressa de um ponto de vista prático, como quando algum repórter diz 'a fonte é confiável', ou quando alguém nos interpela acerca da fonte de uma notícia que a demos se esta é confiável. Fotografias, fósseis, imagens de telescópios espaciais, são verdadeiros recortes estáticos de momentos passados, e a não ser que sejam cópias falsificadas de seus originais, ou montagens, etc., elas parecem gozar de verificação por meio de correspondência, no caso em que o exemplar representa algo que realmente existiu naquele momento passado. Contudo, ainda que se possa obter boas informações a partir desses registros do tempo, qualquer tentativa de dizer deles, não tendo estado lá presente, é meramente conjectural, e só pode obter algum grau de objetividade por mera adesão coletiva. Ainda que as evidências científicas sejam fortes e apoiadas em técnicas sofisticadas, como a datação por radiação, elas são sempre uma estimativa ${ }^{14}$. Uma teoria da crença em relação ao tempo passado deveria se preocupar também com uma investigação sobre o relato histórico pensado como descrição de um fato histórico, e como se constituiriam as relações de acordo entre os falantes nesses casos.

Muitas vezes acreditamos, isto é, estamos convencidos de uma memória por um momento, mas depois ficamos em dúvida se realmente aquilo aconteceu exatamente do modo como descrevemos, como no caso de sonhos, ou memórias antigas. Portanto, deve haver também em enunciados sobre o passado algum elemento subjetivo envolvido na sua verificação; por exemplo, um sujeito convicto de um fato que não

\footnotetext{
${ }^{13}$ Além desses dois fatores, não poderíamos deixar de mencionar o papel da memória na atribuição de validade a um enunciado sobre o passado. Dancy (1990 p. 228) define a posição epistemológica realista com relação à memória como "o ponto de vista de que a ocorrência de memórias atuais e a possibilidade de outras memórias que não as que atualmente temos, têm qualquer coisa de inteiramente diferente dessas memórias." Sob esta perspectiva, a referência dos enunciados sobre o passado seria dada pela descrição de fatos passados. Já o realista indireto afirma que "quando recordamos, há um objeto direto de consciência que funciona como intermediário; é a imagem da memória." Nesse sentido, a referência dos enunciados sobre o passado seria dada pela descrição de uma representação, a qual pode variar de um sujeito a outro (p. ex. um mesmo acontecimento visto por sujeitos a partir de ângulos diferentes), o que põe em questão a validade objetiva desses enunciados. Destacamos aqui que o caráter da crença, diante dessas dificuldades, pode ser um caminho teórico interessante para estudar a atribuição de validade objetiva, em uma comunidade, a acontecimentos passados.

${ }^{14}$ Desse modo, enunciados científicos sobre o passado gozariam de objetividade por serem validados por um método (p. ex. a datação por carbono 14) bem estabelecido e aceito por uma comunidade científica, mas jamais seria possível a sua verificação direta, por se tratarem de juízos sobre o passado, como por exemplo em "a datação por carbono 14 indica que o espécime tem mais de 5 mil anos".
} 
aconteceu jamais o tomará como falso, e dificilmente alguém o convencerá do contrário, ainda que nem ele nem o interlocutor possam fornecer provas definitivas. Um conjunto de pessoas envolvidas em uma sociedade guiada por alguns enunciados admitidos como verdadeiros também pode, por mera adesão coletiva, estarem justificados a crer num acontecimento passado. A morte de um mártir, relatos de fatos milagrosos, todos esses enunciados sobre o passado podem obter justificação coletiva, mas não objetividade.

\subsection{Enunciados sobre o tempo futuro}

Se alguém me diz 'amanhã vai chover em Brasília', que critérios eu utilizo para verificar a validade desse enunciado? Eventos passados, quando vivenciados pelos dois falantes, permitem uma verificação direta, enquanto que quando um dos dois não esteve presente, apenas por concessão. Eventos futuros, contudo, não foram vivenciados por nenhum dos dois falantes. Do ponto de vista da possibilidade lógica, pode ser que esse enunciado venha ou não a ser atestado pela experiência amanhã. Digamos que essa pessoa começa a me fornecer uma série de razões a fim de me convencer acerca da validade de seu enunciado, proferido no momento presente, sobre o futuro; tais como, 'o mapa meteorológico mostra aproximação de um grande volume de nuvens vindas do leste', ou 'veja como o céu está nublado'. Eu posso aceitar por mera concessão, mas nem eu, nem o sujeito que proferiu o enunciado estamos asseguradamente certos de que ele se verificará no dia seguinte. A possibilidade de que um vento vindo do oeste devolva aquelas nuvens ao seu lugar de origem é a mesma de que ela permaneça em Brasília e venha a precipi$\operatorname{tar}{ }^{15}$. Sob esta perspectiva, toda afirmação sobre o futuro, sob esta perspectiva, só pode dizer respeito a uma possibilidade de que algo aconteça. Enunciados científicos, futurologias, cartomantes, leitores de mãos, e todos os enunciados que pretendem dizer de algo que ainda não aconteceu o modo como vai acontecer, só podem ter a chance de vir a acertar caso refinem seu enunciado com uma série de definições auxiliares que permitam aumentar as chances de

\footnotetext{
${ }^{15}$ Um exemplo clássico do tratamento desse problema na tradição filosófica é o problema levantado por Hume e a resposta a ele dada por Kant. Hume afirma que "o contrário de toda questão de fato deve sempre permanecer sendo possível, porque não pode implicar jamais em contradição" (Investigações, seção IV. § 2). Além disso, Hume assume a impossibilidade de conhecimento $a$ priori da relação de causa e efeito (ibdem $\S 6$ ), pois como o efeito é algo distinto de sua causa, ele não pode ser descoberto na própria causa. (ibidem $\S 11$ ). Disso resulta a atribuição de mera probabilidade a juízos baseados em experiências passadas para se referir a acontecimentos futuros (ibdem $\S 19$ ), e a fundamentação no hábito ou no costume daquilo que nos faz esperar para o futuro o que ocorreu em experiências passadas (ibidem, seção V § 5-6). Referindo-se a essa noção acerca da relação de causa e efeito, Kant afirma (KrV B 794) que "Hume concluiu pois, falsamente, da contingência de nossa ação de determinar segundo a lei, a contingência da própria lei e confundiu a passagem do conceito de uma coisa à experiência possível (a qual sucede a priori e exprime a realidade objetiva desse conceito com a síntese dos objetos na experiência rela que, na verdade, é sempre empírica."
} 
que seu enunciado venha a se conferir 16 , Geralmente o cientista faz suas definições auxiliares baseado no estabelecimento de certas condições experimentais, enquanto que aquelas espécies de místicos citadas baseiam suas definições auxiliares nos enunciados que servem para o maior número de possibilidades, por exemplo, 'eu vejo que você passará por um momento difícil na sua vida'; ora, muitos eventos podem ser denotados por um enunciado como esse, e o ouvinte incauto pode facilmente vir a admitir validade a um enunciado que as vezes não passa de mera charlatanice. Porém, enunciados científicos gozam de um prestígio o qual se afasta radicalmente do misticismo, apesar de compartilharem esse interesse em enunciar acerca de eventos futuros. Mas a ciência, diferente do misticismo, acerta muito mais, isto é, em termos estatísticos, se contássemos em uma competição entre um cientista e um místico, qual deles acertou mais previsões acerca do futuro, o cientista sairia ganhando. Portanto, deve haver alguma característica no enunciado científico que o diferencia do simples misticismo, e essa característica é a capacidade de previsibilidade acertada. O místico amplia o escopo de definição do seu enunciado, o cientista restringe. Tal restrição, contudo, tem um preço, qual seja, o cientista deve se contentar em jamais conhecer o objeto em questão na totalidade das variáveis que ele deve desprezar para que seu enunciado seja capaz de prever um acontecimento futuro 17 .

Aqui também intervém a noção de confiabilidade, pois se um místico me dissesse aquela frase, e um meteorologista me dissesse que não será o caso, certamente eu não levaria o guardachuva para a universidade no dia seguinte. Contudo, essa confiabilidade só é conferida ao cientista porque sabemos que ele é uma pessoa experimentada naquele tipo de situação, que dispõe de uma série de informações que refinam a sua crença de que aquele evento irá mesmo acontecer, que dispõe de uma instrumentação adequada e de uma linguagem igualmente adequada para a avaliação da possibilidade de ocorrência do fenômeno meteorológico, etc.

Contudo, o cientista trabalha sempre com aproximações, isto é, tratamentos estatísticos que levam em consideração erros aleatórios, erros sistemáticos, dispersão de dados, e outros cálculos que o permitem dizer, com alguma margem de erro, acerca de alguma caracterís-

\footnotetext{
${ }^{16}$ Com relação aos juízos científicos, Hume (Investigações, seção IV. § 12) afirma que "A mais perfeita filosofia da espécie natural apenas detém por algum tempo nossa ignorância [...]". Kant via nisso (KrV B 128) um mal resultado do ceticismo humeano: "a derivação empírica a que ambos recorreram [Locke e Hume], não se coaduna com a realidade dos conhecimentos científicos a priori que possuímos, ou seja, os da matemática pura e os da ciência geral da natureza, sendo, por conseguinte, refutada pelo fato.".

${ }^{17}$ Em enunciados científicos, frequentemente é preciso se desconsiderar algumas variáveis a fim de tornar esse enunciado mais geral, como por exemplo, "desprezando a resistência do ar a aceleração de um corpo em queda nas proximidades da crosta terrestre é aproximadamente $9,8 \mathrm{~m} \cdot \mathrm{s}^{2}$ ", ou ainda "sob as condições padrão de temperatura e pressão...". Afirmamos que é nessa restrição de variáveis que o cientista aumenta as chances de que seu enunciado seja bem sucedido em um evento futuro.
} 
tica qualitativa ou quantitativa do fenômeno estudado com algum intervalo de confiança específico. Como no experimento científico são estabelecidas as condições ideais para que um fenômeno ocorra, a coerência do enunciado científico é em grande parte dada por essas restrições ${ }^{18}$. Caso vários outros cientistas estrangeiros repitam aquele experimento, sobre as mesmas condições, e o evento se repita conforme previsto pelo enunciado, então aquele enunciado é um princípio. Note, porém, que ainda que o enunciado venha a ser verificado, ele deve sempre lidar com uma série de condições possíveis que escapam de seu controle $\sqrt{19}$, sendo sempre necessário um tratamento estatístico adequado para que seja conferido ao enunciado alguma confiabilidade. Assim o cientista não deveria fazer afirmações categóricas acerca da experiência, mas apenas hipotéticas, de modo que mesmo aquilo que é tido como uma lei científica deve ser tomado como passível de contrariedade num evento futuro.

Mas então o que garante a um enunciado científico a sua confirmação futura? Somente aproximações e tentativas mais ou menos bem refinadas que aumentando o número de critérios auxiliares acaba diminuindo as possibili- dades, mais nunca as eliminando completamente de modo que só reste a possibilidade de que aconteça aquilo que foi enunciado. O cientista só pode contar, assim, para a justificação de seus enunciados, com o procedimento lógico da indução, isto é, a partir da observação de que vários casos diferentes se passaram de modo semelhante, posso inferir que casos que se enquadrem naquelas mesmas condições se passarão de modo semelhante; Hume viu nesse procedimento uma espécie de associação psicológica (Investigações, Seção V § 5) a qual não garantia realmente a veracidade desse tipo de enunciado. Porém, a indução pode ser vista como um passo positivo no processo de aquisição de conhecimento, e não como uma espécie de artifício do qual se vale o cientista para escapar de uma "impossibilidade total" sobre nossa capacidade de falar com acerto acerca de eventos futuros.

Karl Popper (1972 p. 17) aborda o problema da indução de maneira diversa da de Hume. Popper afirma que Hume formulou o problema de maneira errônea, o que o levou a tentar dar uma resposta a um problema lógico e a um problema psicológico da indução: o primeiro deles é o de se estamos justificados, no conhecimento, a partir de

\footnotetext{
${ }^{18}$ Geralmente nos laboratórios a reprodução bem sucedida de um experimento está condicionada a determinadas condições físicas (p. ex. pressão, temperatura) ou mesmo químicas (p. ex. concentração, pH) ideais. Além disso os instrumentos utilizados nos experimentos (vidrarias, balanças, etc.) são constantemente submetidos a calibrações e os resultados empíricos das medidas sempre passam por um tratamento estatístico. Veja' : (SKOOG, Douglas A. [et all], 2009. P. 132)

${ }^{19}$ Isto é, o que em estatística é conhecido como "erro aleatório". Segundo Skoog (2009 p. 98) “Os erros aleatórios, ou indeterminados, existem em todas as medidas. Jamais podem ser totalmente eliminados e são, muitas vezes, a maior fonte de incertezas em uma determinação."
} 
experiências conhecidas a experiências desconhecidas; a segunda é tentar responder no que se fundamenta a nossa expectativa de que as experiências desconhecidas serão como as conhecidas. Ele a firma ainda que

Seu resultado de que a repetição não tem qualquer força como argumento, embora domine nossa vida cognitiva ou nosso "entendimento", levouo à conclusão de que o argumento, ou a razão, desempenha apenas um papel menor em nosso entendimento. (Popper, 1972 p. 16)

Popper propõe então "traduzir todos os termos subjetivos ou psicológicos, especialmente "crença", etc., em termos objetivos [...] e em vez de "justificativa de uma crença" falo de "justificativa da alegação de que uma teoria é verdadeira", etc." (ibidem p. 17). Chama então de "asserções de teste" nossas asserções mais básicas, as quais podem ser dados exemplos na experiência, e aquelas a que não podem, "teorias explanativas universais". A sua solução do problema da indução consiste primeiramente em admitir, como fez Hume, a impossibilidade de justificar uma teoria universal a partir da verdade de asserções de teste, seja qual for o nú- mero de repetições, para em seguida concluir que "a admissão da verdade de asserções de teste às vezes nos permite justificar a alegação de que uma teoria explanativa universal é falsa."(ibidem). Nesse caso, "como estamos em busca de uma teoria explanativa verdadeira, preferimos aquela cuja falsidade ainda não foi estabelecida"(ibidem), portanto, a partir da refutação de uma asserção de teste por outra em decorrência da concorrência entre teorias, mantemos aquela cuja falsidade não foi apresentada por nenhuma daquelas asserções de teste.

A indução tem funcionado e ainda funciona muito bem; se um técnico de laboratório sabe que o material do qual é feito uma câmara de gás só resiste a determinada pressão, jamais preencherá a câmara a um ponto que ultrapasse a capacidade de resistência daquele material, pois sabe que o resultado esperado é uma explosão; desse modo, ele pode todas as vezes em que duvidar dessa afirmação, testá-la no tempo presente em qualquer que seja o tempo futuro, caso repita as mesmas condições. Assim, se o cientista decide assumir uma posição epistemológica do tipo realista, isto é, segundo a qual seus enunciados diriam respeito a objetos em $s{ }^{20}$ dados independentemente das regras de sua linguagem, ele não pode requerer para seus enunciados que sejam válidos para condições futuras, pois ele

\footnotetext{
${ }^{20}$ Nos valendo aqui da distinção que Kant operou entre fenômenos e coisas em si. Veja p. ex. (KrV B 67).
} 
poderá no máximo dizer, sob determinadas condições, que algo pode se passar, com algum grau de certeza.

\section{Consequências práticas dos dife- rentes usos dos enunciados temporais e atemporais}

Tentamos expor até o momento o problema acerca da objetividade de um conhecimento do ponto de vista dos diferentes momentos no tempo aos quais o enunciado se refere. Assim, chegamos a algumas conclusões principais: 1) enunciados sobre entidades metafísicas são atemporais, embora possam conter predicados temporais; seu principal critério de verificação consiste numa coerência lógica interna ao sistema, relacionada com a adesão coletiva e a crença subjetiva. 2) existem três tipos de enunciados temporais, presente, passado e futuro, cada um deles com critérios de verificação particulares. O critério de verdade como correspondência só vale para o presente, de modo que para valer no passado, deve ser em relação ao presente do pretérito, tendo estado o interlocutor presente. Estando ele ausente, vale o critério de confiabilidade ou mera concessão. A aleatoriedade do possível faz com que esse princípio seja inválido para o futuro, a não ser no momento presente em que ele se realize no futuro. No melhor dos casos possíveis, ou seja, nas ciências, o falante só pode contar com aproximações a partir de tratamentos estatísticos dos dados e com a probabilidade de que o enunciado se verifique. Em todos os casos, evidencia-se que o caráter epistemológico da crença está intimamente associado ao convencionalismo de certos usos, às adesões subjetivas, ou coletivas, voluntárias, e a uma espécie de confiabilidade. Isso tem uma série de consequências práticas para diferentes domínios do corpo social humano, pois a crença cria e destrói instituições, povos e estados.

\subsection{Religião, História e "Fake News"}

A maioria das religiões que conhecemos está baseada em um livro, ou conjunto de livros, que contém seus principais preceitos, relatos de atos divinos, etc. Em última instância, nada do que está escrito num desses livros pode ser provado, no sentido estrito deste termo. Que Moisés tenha aberto o Mar Vermelho ou que Maomé tenha viajado de Meca até Medina, é algo que eu jamais poderei saber com certeza absoluta, ainda que o segundo acontecimento acima seja mais plausível que possa ter acontecido do que o primeiro. A institucionalização das religiões é um dos exemplos mais evidentes de como a noção de verdade de um enunciado está intimamente ligada com fatores convencionais, crenças coletivas de cunho subjetivo, de modo que isso tem implicações práticas notáveis.

Uma pessoa educada segundo os 
preceitos de uma religião jamais vai abandoná-los, seja por um momento, num momento em que esteja avaliando seja um dado empírico, seja o comportamento de uma pessoa, e isso vai influenciar na hora de avaliar a validade dos enunciados que provenham de um contexto outro que não o religioso. Um padre versado em astronomia, quando observa o movimento de um astro, glorifica a Deus como o agente secreto daquele movimento. Esse mesmo sujeito diante de um ateu que tente convencerlhe da inexistência de Deus, se der atenção àquele, será apenas uma atenção de ouvidos, porque o seu cérebro permanecerá relutante em tomar qualquer um daqueles argumentos como válido. Todos nós conhecemos mais ou menos bem as consequências práticas desse tipo de crença, mas o que nos chama a atenção nesse caso é que um conjunto de crenças estabelecidas, por assim dizer, de fora do sujeito, são capazes de causar consequências práticas interiores, isto é, que dizem respeito à subjetividade, tal como a tomada de decisões, e mesmo a orientação de toda uma vida segundo aqueles preceitos, como no caso das freiras, padres, etc. Além de se basear em enunciados sobre eventos passados, as religiões tem a pretensão de dizer acerca de eventos futuros, como nos casos de apocalipses e messianismo.

Mais importante do que o evento histórico a ser relatado, é quem relata o evento histórico. Comumente, chama- mos 'ponto de vista' a interpretação que depende sempre do sujeito que a relata. Um evento histórico sempre possui diferentes "pontos de vista". Um americano patriota pode crer que as bombas lançadas sobre o Japão foram em prol da manutenção da paz mundial, o que pode não condizer com a verdade, ainda que isso possa estar presente em alguns livros didáticos de história em inglês. Desse modo, a interpretação de um acontecimento que se converte em um relato sobre o mesmo deve ser destacada do próprio acontecimento ou evento. Mas, podemos dizer que o simples relato do lançamento das bombas é factual? De modo rigoroso, não. Porém, há um número enorme de evidências que servem como provas auxiliares ao mero relato, que fortalecem a confiança nele, e que nos faz crer que de fato aconteceram, mas que jamais obterão de nós a verificação absoluta. Se formos radicais, tudo aquilo que eu não vivi, e de que não tenho uma memória viva, apenas pode ter ocorrido; junte a isso um conjunto de provas auxiliares e eu lhe concedo meu 'sim, você tem razão'.

Atualmente temos presenciado na mídia internacional vários exemplos de usos de notícias falsas que alteraram o curso de eleições, e de maneira mais trágica, determinaram a morte de algumas pessoas. A tomada de um relato como evidente por sua mera repercussão é uma modalidade desse tipo de crença, e podemos dizer que elas vêm a ser aceitas como válidas de maneira geral por 
adesão coletiva. Assim, de maneira geral, esses enunciados presentes em livros de história, notícias, e em preceitos que regulamentam instituições que tem a pretensão de obter validade acerca de enunciados sobre o tempo passado, obtêm por adesão. Fora do círculo de validade desses enunciados, isto é, da comunidade que os assume e sustentam, eles não obtêm validade alguma.

\subsection{Direito}

Quando penso no trabalho de um juiz de direito, sinto uma certa aflição em me colocar no lugar desses profissionais. Isso porque na maioria dos casos em que se tem que julgar um crime, por exemplo, o juiz só pode contar com a argumentação da acusação e da defesa, defendendo seu ponto de vista sobre o que aconteceu. Para que convençam o juiz, seja a acusar seja a absolver, o promotor e o advogado apresentam uma série de fatos, baseados em provas, tendo estas últimas de estarem de acordo com a legislação. A defesa poderia dizer algo como 'posso provar que meu cliente estava em um local bem distante, no horário em que o crime ocorreu', e até apresentar algumas provas, como ter assinado a chamada da aula de inglês que ocorreu naquele mesmo horário; porém, o juiz nunca saberá com cem por cento de certeza se aquele documento não é uma fraude. O advogado de defesa chama o professor como testemunha, o qual afirma ter visto seu cliente na sala de aula naquele horário, mas o professor afirma isso com uma certa dúvida, ele não tem bem certeza, quando indagado acaba errando a cor da camisa que o cliente usava naquele dia; enfim, nunca saberemos se o professor não o confundiu com algum outro aluno, se alguma circunstância outra aconteceu, ou se era o caso que se tratava daquela pessoa.

Se, por um lado, não deve interferir no direito as inclinações pessoais do juiz, mas tudo deve ser provado mediante a letra da lei, por outro lado, as decisões que levam em consideração somente um ponto de vista técnico podem, devido ao preceito de cumprir a lei a qualquer preço, acabar condenando um inocente, ou libertando um culpado. Portanto, o juiz não pode contar nem com uma técnica bem estabelecida nem com suas inclinações pessoais, mas deve ter uma certa capacidade de dedução dos fatos que lhe são apresentados, a fim de ver se cabe a esses fatos aplicar alguma sanção. Mas e se um dos dois, acusação ou defesa, tiver uma capacidade de exposição de seus argumentos de maneira mais clara, mais em conformidade com a lei, mais inteligível para os que estão ali presentes, do que o outro? Será que de maneira alguma isso interferiria no resultado de um julgamento? E quando se trata de um caso de forte apelo popular, o direito se mantém isento de qualquer interferência pragmática da linguagem 
em suas decisões? Nunca saberemos, em nenhum desses casos, se o réu realmente cometeu o crime ou não, pois trata-se de um caso passado, de onde, à semelhança de casos futuros, só podemos tirar vestígios ou conceder veracidade aos enunciados.

A filmagem, a fotografia, são elementos de prova muito fortes, porém, mesmo sobre eles ainda se pode levantar dúvida acerca de sua veracidade; em uma situação possível poderiam os defensores, quando seus clientes são apanhados por uma câmera bem no momento em que estão recebendo uma mala de dinheiro, alegar que 'não se trata do cliente, mas de uma outra pessoa, devido a qualidade da imagem, etc'. Quem prova, de maneira definitiva e de uma vez por todas, que realmente era a pessoa em questão? Acreditamos que essa incompletude das sentenças e das provas no direito se deve ao fato de que se tratam de proposições sobre o passado, pois primeiro ocorre o crime, depois se tem relatos dele, para enfim serem julgados. Mesmo nos casos em que ocorre o flagrante no momento em que o crime está sendo cometido, como quando um policial apanha um criminoso no ato, por exemplo, é preciso que haja testemunhas do flagrante quando este reportar o crime ao poder judiciário. O caso mais extremo a ser pensado para se alcançar a completude no di- reito é se o juiz estivesse presente no momento do crime e ali mesmo pudesse proferir sua sentença, o que obviamente não ocorre. Mas, como sabemos, o direito está repleto de costumes e de ritos que são seguidos por todos os seus praticantes; é uma prática comum dos demais tribunais seguirem o entendimento dos colegiados superiores (como o Supremo Tribunal Federal ou o Superior Tribunal de Justiça) os quais tomam suas decisões a partir da maioria dos votos acerca do que está sendo pautado. Jamais saberemos acerca da 'imparcialidade' de cada juiz em relação a sua decisão, portanto, em casos de decisões colegiadas no direito impera a interpretação de cada magistrado, o que mostra um assustador caráter subjetivo nas decisões judiciais. Imagine um juiz racista julgando um negro.

\subsection{Linguagem cotidiana e convencio- nalismo 21}

É bastante comum nas conversas do dia-a-dia as pessoas se pronunciarem acerca de algo que se passou, algo que está se passando agora, ou algo que pode se passar. É difícil pensar em situações em que nenhuma modalidade temporal esteja envolvida. Uma pessoa pode ainda se referir a uma ideia, ou a uma imaginação, um plano, uma

\footnotetext{
${ }^{21}$ Em seu dicionário, Abbagnano define o termo "convencionalismo" da seguinte maneira: "Qualquer doutrina segundo a qual a verdade de algumas proposições válidas em um ou mais campos se deva ao acordo comum ou ao entendimento (tácito ou expresso) daqueles que utilizam essas proposições". Tomamos para o presente artigo esse sentido de convencionalismo.
} 
equação, ou um esquema; diríamos que nesses casos ela se refere a algo sem o uso de nenhuma daquelas modalidades? Pois se o sujeito não fala de algo que está fisicamente presente, ou fala de algo do passado, ou do futuro, ou se refere a alguma ideia ou pensamento seu ou de outrem, excluído é claro a interrogação, a exclamação, e diferentes usos como ordenar, pedir, chamar, etc. Por isso, se tratando de frases assertivas, em geral elas fazem referência a uma das modalidades temporais. Numa frase do tipo 'este x é $y^{\prime}$, tratase sempre do momento presente, pois o predicado é ligado ao sujeito pelo verbo ser conjugado no tempo presente, e assim para as demais modalidades. E quando o sujeito se refere a uma ideia sua ou a de outrem, tal como na frase 'a ideia leibniziana de mônada', podemos atribuir alguma modalidade temporal? Ou numa frase como 'eu penso que podemos entender a vida como provação', podemos dizer que não existe nenhum resquício de temporalidade? Acreditamos que não, e que isso não implica em assumir nenhum compromisso ontológico, tal como dizer que se é atemporal é eterno, ou algo assim. Acreditamos que isso se deve à vaziez da referência a que esse tipo de enunciado manifesta, e com isso queremos dizer que somente enunciados temporais são passíveis de referencialidade, direta e indireta.

Percebemos com isso que, na linguagem cotidiana, os falantes intercalamse entre enunciados temporais e atem- porais, e que a verificação desses enunciados de maneira geral, se dá ora por concordância lógica, ora por concordância coletiva, sendo esta última composta por enunciados convencionais, de tal modo que a depender da instituição, grupo ou casta esses enunciados adquirem um valor de verdade, uma confiabilidade, e uma consequente aceitação coletiva que determinará também o modo como qualquer evento particular pertencente a um conjunto de eventos que não se enquadram segundo aquelas regras deverá ser avaliado. Numa conversa cotidiana, geralmente quando alguém se refere a um evento passado, aceita-se a validade do enunciado por mera concessão, ao presente por referência, $e$ ao futuro por possibilidade. A detecção de mentiras, fabulações, histórias imaginadas, sobre o passado, se dá ou pela incongruência e impossibilidade de ocorrência do fato enunciado, ou pela percepção de certos aspectos psicológicos como insegurança ao falar, ou não olhar para os olhos do interlocutor, apesar de nada disso ser definitivo.

Um aspecto prático da modalidade temporal na fala cotidiana também se mostra na alteração do código que acontece com a adesão ou retirada de termos novos ou antigos da linguagem em questão, ou a adesão a novas regras. É bastante perceptível como alguns senhores mais velhos ficam deslocados em uma reunião de jovens, e como esses últimos são relutantes em aceitar em seus grupos culturais locais 
outros membros que não compartilhem de uma cultura linguística mínima, isto é, que compartilhe da mesma temporalidade cultural vigente naquele grupo. Talvez a incapacidade de alguns jovens em conseguir encontrar um grupo no qual possa fazer amigos se dê por conta da incapacidade desse jovem em compartilhar de regras linguístico-culturais mínimas que permitem uma primeira interação. Pessoas que compartilham de um mesmo gosto musical, estudam um mesmo tema, e, em última instância, falam a mesma língua, tem muito mais facilidade para o contato social. Esse fenômeno linguístico é muito interessante, porque ele acaba implicando ou em adesão ou abandono do indivíduo em relação ao grupo ou deste em relação ao indivíduo. É bastante comum ouvirmos pessoas mais velhas dizendo algo como 'na minha época tal coisa não se passava assim', com o fim de apresentar alguma lição de moral ou algo parecido ao interlocutor, o que pode apenas ser uma fabulação daquele que a profere, mas uma fabulação com efeitos práticos.

Dificilmente nós diríamos que a noção de tempo apresentada por Einstein no século XX já se tornou popular, a ponto de estar subentendida quando um falante comum profere a palavra 'tempo' em alguma frase. Assim, talvez sejam permitidos novos tipos de construções frasais acerca de uma concepção de tempo que não seja entendida como dividida nos três momentos, ou talvez enunciados sobre o passado ou o futuro que permitam uma verificação direta. Isso mostra que observando a capacidade de enunciação sob o ponto de vista do tempo nós podemos perceber que existe associado a eles um elemento intrínseco de convencionalismo, de uma aceitação geral de determinada noções que significam esses enunciados, e que em última instância vão determinar, em alguns casos, a verificação de enunciados que tem efeitos práticos, mas que não gozam de uma verificação autônoma, isto é, que contenha elementos livres de convencionalismo, inclinação pessoal ou adesão coletiva.

\section{Conclusão}

Uma teoria da crença que leve em consideração os diferentes tempos aos quais os enunciados se referem deveria então conter as regras segundo as quais é feita essa referência de acordo com cada momento do tempo (passado, presente, futuro), de modo a indicar em cada um deles a vigência dos princípios de validação, que culminam na crença daquele que atesta a validade a um enunciado. Tomamos neste ensaio o princípio de verdade enquanto correspondência para testar se tal alternativa seria viável, e vimos que temos alguns indícios a esse respeito. A fala cotidiana, das famílias, das senhoras que falam sobre a novela, está repleta de referências a elementos temporais, e um es- 
tudo pragmático dessa caraterística poderia ser reveladora de alguns aspectos subjacentes a essa fala cotidiana. Isso nos mostra que existem alguns elementos subjacentes à fala comum que só uma pragmática linguística pode sistematizar, pois os critérios de estabelecimento da verdade e sua consequente aceitação pública são a própria estrutura mesma da linguagem cotidiana.

É importante ressaltar aqui que verdadeiro e falso, sob esta perspectiva, pode significar algo a mais do que um valor lógico de verdade para certas proposições; por exemplo, se uma senhora diz a outra a sua opinião sobre um personagem de alguma novela, 'você percebeu o comportamento vil de dona Mercedes?' e a outra responde 'Deus me livre!', eu acho difícil pensar que a resposta da segunda se segue logicamente da proposição da primeira, apesar de se tratar de uma espécie de confirmação pela segunda interlocutora acerca do enunciado da primeira. Assim, uma teoria da crença como uma concessão de validade de um enunciado acerca do momento passado, como no exemplo acima, poderia ser uma alternativa para a explicação da valoração atribuída aos enunciados ouvidos nos casos em que não cabe a mera coerência lógica. Há ainda aqueles que escapam a qualquer regra de tempo, como os enunciados que se referem a ideias, mas que também deveriam fazer parte de uma teoria da crença que leve em consideração as modalidades de tempo empregadas nas falas cotidiana, metafísica e científica. Essa teoria deveria levar em consideração também os aspectos que a sociologia e a antropologia revelam de acordo com as épocas, pois esse estudo revelaria que as regras que determinam os 'jogos de linguagem', como dizia Wittgenstein, recebem do campo sociológico e até mesmo psicológico as bases ideológicas de fundamentação das crenças.

Mesmo diante das alterações sobre a noção de tempo é bastante difícil conceber uma frase como 'amanhã eu fui à casa de Fabrício', em alguma concepção de tempo possível, como passível de justificação. Ou a concepção tripartite do tempo está enraizada em nossos cérebros, ou poderá ser que um dia uma alteração da noção de tempo incida numa determinação de novas combinações de regras possíveis. De todo modo, percebemos que em geral alterações drásticas nas nossas concepções científicas fundamentais acabam resvalando em concepções usuais, como espécies de resquícios seus, que não gozam do mesmo rigor enunciativo, mas que guardam o seu formato. Caberia a uma pragmática linguística que leve em consideração nossa noção de tempo, então, investigar se existem mesmo essas mudanças de paradigma em relação a noções fundamentais como a de tempo. Se elas não existem, então uma alternativa ao investigador seria conceber essa noção como fazendo parte da constituição intrínseca do nosso aparato cogni- 


\begin{abstract}
tivo, de modo que seria impossível pensar construções frasais que se estendessem para além de seu domínio, com ex-
\end{abstract} ceção daquelas que se referem ao domínio metafísico.

\title{
Referências
}

ARISTÓTELES. Metafísica. Tradução: Giovanni Reale. São Paulo: Edições Loyola, 2002.

AUSTIN, J. L. Quando dizer é fazer. Tradução: Danilo Marcondes de Sousa Filho. Porto Alegre: Artes Médicas, 1990.

BACON, Francis. O progresso do Conhecimento. Tradução, int. e notas: Raul Fiker. São Paulo: Editora UNESP, 2007.

DANCY. Jonathan. Epistemologia Contemporânea. Tradução: Teresa Louro Pérez. São Paulo: Edições 70, 2002.

DESCARTES, René. Meditações Metafísicas. Tradução: Maria Ermentina Galvão. São Paulo: Martins Fontes, 2005. . Princípios da Filosofia. Tradução: João Gama. São Paulo: Edições 70.

CASTRO, Armando. Teoria do Conhecimento Científico. Lisboa: Instituto Piaget, 2001.

DUTRA, Luís Henrique de Araújo. Verdade e investigação: o problema da verdade na teoria do conhecimento. São Paulo, EPU, 2001.

FRIEDMAN, Michael. Foundations of space-time Theories. New Jersey: Princeton University Press, 1983.

HABERMAS, J. Verdade e Justificação: ensaios filosóficos. Tradução: Milton Camargo Mota. São Paulo, Edições Loyola, 2004.

HUME, David. Investigações sobre o entendimento humano e sobre os princípios da moral. Tradução: José Oscar de Almeida Marques. São Paulo, Editora Unesp, 2004.

KANT, Immanuel. Crítica da Razão Pura. Tradução: Manuela Pinto dos Santos e Alexandre Fradique Morujão. $7^{\text {a }}$ Edição. Lisboa: Fundação Kalouste Gulbenkian, 2010.

. Prolegômenos a qualquer metafísica futura que possa apresentar-se como ciência. Tradução: José Oscar de Almeida Marques. São Paulo: Estação Liberdade, 2014.

LOCKE, John. Ensaio Sobre o Entendimento Humano. Tradução: Pedro Paulo Garrido Pimenta. São Paulo: Martins Fontes, 2012.

MENEZES, Djacir. O problema da realidade objetiva. 2a Ed., rev. E ampl.; Rio de Janeiro: Tempo Brasileiro, 1971.

POPPER, Karl. Conhecimento Objetivo: uma abordagem evolucionária. Tradução de Milton Amado. Belo Horizonte: Ed. Itatiaia; São Paulo, Ed. da Universidade de São Paulo, 1975.

SKOOG, Douglas A. [et all...] Fundamentos de Química Analítica. Tradução: Marco Grassi. São Paulo: Pioneira Thomson Learning, 2006.

TARSKI, Alfred. The Semantic Conception of Truth: and the foundations of Semantics. Philosophic and Phenomenological Research, Volume 4, Issue 3. (Mar. 1944), 341-376.

Recebido: $04 / 01 / 2020$

Aprovado: $21 / 09 / 2020$

Publicado: $30 / 12 / 2020$ 
